\title{
Inteligência Estratégica e Design Thinking: Conceitos Complementares, Sequenciais e Recorrentes para Estratégia Inovativa
}

\author{
Marcelo Mesquita Reche \\ Pontifícia Universidade Católica do Rio Grande do Sul (PUC-RS), Brasil \\ marcelom.reche@gmail.com

\section{Raquel Janissek-Muniz} \\ Universidade Federal do Rio Grande do Sul (UFRGS), Brasil \\ rjmuniz@ufrgs.br
}

\section{RESUMO}

Os esforços e investimentos demonstram o foco que as organizações têm em desenvolver inovações em seus segmentos. Com o crescente aumento da competitividade entre as empresas, as ações e o planejamento estratégico são essenciais para a sobrevivência no mercado. Monitorar o ambiente visando identificar novos focos ou formas de atuação é um modo de tornar processuais as iniciativas que podem alavancar o negócio por meio de uma postura proativa. Nesse sentido, o uso do conceito de Inteligência Estratégica, já uma realidade entre as empresas, gera informações importantes para a criação de vantagem competitiva. Já o conceito de Design Thinking é utilizado como método para satisfazer objetivos tanto econômicos quanto criativos. Ambos os conceitos possuem etapas de processo que os caracterizam como cíclicos e que estão diretamente ligadas à estratégia da organização. Neste artigo, a proposta é compreender uma possível correlação entre os conceitos de Inteligência Estratégica e Design Thinking para o desenvolvimento de estratégia inovativa. De abordagem qualitativa, na pesquisa coletaram-se dados junto a profissionais ligados aos conceitos tema deste estudo. Os resultados demonstram uma proximidade entre os métodos de Design Thinking e Inteligência Estratégica, além da complementariedade ou sequencialidade de sua utilização com foco em inovação. 
PALAVRAS-CHAVE: Inteligência estratégica. Design thinking. Inovação. Estratégica inovativa.

\title{
Strategic Intelligence and Design Thinking: Complementary, Sequential and Recurring Concepts for Innovative Strategy
}

\begin{abstract}
Efforts and investments demonstrate the focus that organizations have on developing innovations in their segments. With the increasing increase in competitiveness among companies, actions and strategic planning are essential for survival in the market. Monitoring the environment to identify new focuses or forms of action is a way to make procedural initiatives that can potentially leverage the business through a proactive stance. In this sense, the use of the concept of Strategic Intelligence is already a reality among companies generating important information for the creation of competitive advantage. The concept of Design Thinking is used as a method to satisfy both economic and creative goals. Both concepts have process steps that characterize them as cyclical and that are directly linked to the organization's strategy. This article proposes to understand a possible correlation between the concepts of Strategic Intelligence and Thinking Design for the development of innovative strategy. From a qualitative approach, the research collected data from professionals related to the theme concepts of this study. The results demonstrate a closeness between the methods of Design Thinking and Strategic Intelligence, besides the complementarity or sequentially of its use with a focus on innovation.
\end{abstract}

KEY-WORDS: Strategic intelligence. Design Thinking. Innovation. Strategic innovation 
Existe um denominador que une governos, universidades, investidores e empresas e é motivado pelo foco em inovação. Enquanto as universidades querem reter seus melhores talentos, o governo quer gerar mais empregos e melhorar a economia, já os investidores buscam apenas retorno e lucro. Por fim as empresas buscam desenvolvimento, seja ele regional, nacional ou internacional. São objetivos distintos que permeiam o mesmo caminho, o de inovar (Ben-Israel, 2012, p. 24).

Para Collet (2012), o dinamismo do mercado traz desafios para as organizações. As relações de mercado transformam-se com rapidez, as tecnologias desenvolvem-se cada vez mais rápido, a forma de trabalho nas empresas modifica-se a cada dia e, assim, torna-se imprescindível inovar constantemente para manter-se competitivo e buscar desenvolvimento econômico e social.

De acordo com Santos (2014), as organizações buscam ter capacidade de inovação, o que se refere à forma de gerar, criar e desenvolver inovações com foco em produto ou serviço. Esse esforço de inovação visa ao desenvolvimento de oportunidades e ao maior desempenho no mercado.

Já que o dinamismo do ambiente externo das organizações toma proporções cada vez maiores ao passo do crescimento tecnológico, exige-se das empresas que respondam com agilidade e antecipem cenários a fim de atender às demandas do consumidor e garantir vantagem competitiva (Santos, 2014).

Para isso, as organizações necessitam de inovações que façam a diferença, com uma abordagem eficaz e acessível sendo integrada a todos os aspectos de negócio, da sociedade e de indivíduos que possam gerar ideias inovadoras. Para estabelecer esse fluxo de ideias capazes de desenvolver soluções e novas estratégias, é possível a utilização da abordagem de Design Thinking, que se baseia na capacidade de os indivíduos reconhecerem padrões, desenvolverem ideias e serem intuitivos, utilizando o emocional acima do funcional. No entanto as organizações não querem basear suas tomadas de decisões em sentimentos e intuição devido à incerteza; por outro lado ser apenas racional tende a ser tão inseguro quanto (Brown \& Katz, 2010).

Todo o esforço de inovação possui cunho estratégico para as organizações e sua definição pode ser permeada por esforços de monitoramento de ambiente na busca de sinais ou insights relevantes para o negócio. O monitoramento do ambiente pode ser realizado por meio de atividades de inteligência estratégica, dentre as quais há a Inteligência Estratégica Antecipativa, que auxilia as organizações nos pilares estratégicos por meio da antecipação das mudanças em seu ambiente socioeconômico e no direcionamento de como implementar ações. Por meio de métodos próprios, a IEAc apoia as empresas no processo decisório para que possam agir no 
momento certo, pela representação do ambiente e possíveis mudanças que sejam do interesse da organização (Janissek-Muniz, Lesca \& Freitas, 2011).

A estratégia empresarial mais adequada para a organização é a que possa diferi-la de forma favorável de seus concorrentes. Sendo assim, a vantagem competitiva é resultado da estratégia da organização dentro do ambiente onde atua (Oliveira, 2001).

Segundo Júlio (2005), a vantagem estratégica está em identificar oportunidade de negócio e transformá-la em objetivo. Existem dois tipos de oportunidades: ambientais e empresariais. A oportunidade ambiental manifesta-se no mercado e é acessível a todos os competidores. Já a oportunidade empresarial é exclusiva da organização ou pode ser mais bem utilizada pela empresa frente aos concorrentes. Dessa forma, a proposta de Inteligência Estratégica está em analisar o ambiente da empresa, interno e externo, para identificar as oportunidades pertinentes à organização. O conceito de Design Thinking como ferramenta contribui de modo semelhante para a empresa e seu posicionamento.

A Inteligência Estratégica e o Design Thinking possuem similaridades em seus processos, mas trabalham com etapas distintas. Acredita-se ser necessário compreender se há a possibilidade de ser exercida uma complementaridade e inter-relação entre ambos para a tomada de decisão na organização e no âmbito estratégico.

Nesse contexto, é apresentada a seguinte questão de pesquisa: Como os conceitos de Inteligência Estratégica e Design Thinking podem colaborar de forma conjunta para o desenvolvimento de Estratégia Inovativa?

Dessa forma, este artigo tem como principal objetivo compreender uma possível correlação entre os conceitos de Design Thinking e Inteligência Estratégica para o desenvolvimento de inovação pelas organizações, tendo como objetivos específicos (i) descrever os processos que envolvem os conceitos de Inteligência Estratégica e Design Thinking; (ii) estruturar um comparativo e relacionar os conceitos de IE e Design Thinking; e (iii) apontar os aspectos complementares, sequenciais e recorrentes no desenvolvimento dos métodos.

Depois desta introdução, este artigo assim se estrutura: na seção 2, apresenta-se a revisão da literatura, contendo a base dos conceitos de Design Thinking, Inteligência Estratégica e Estratégica de Inovação, tendo como foco principal a inovação de produtos e serviços; na seção 3, apresenta-se o método de pesquisa; na 4, a apresentação e análise dos resultados; e, por fim, na seção 5 , as considerações finais. 


\section{O Design Thinking E A INTELIGÊNCIA ESTRATÉGICA PARA A ESTRATÉGIA DE INOVAÇÃO}

É possível afirmar que tanto o Design Thinking quanto a Inteligência Estratégica são meios para se chegar à estratégia inovativa ideal e necessária para a organização. No entanto por mais que a inovação seja um tema bastante discutido nas empresas atualmente, não há uma descrição exata e definitiva de como obter sucesso com inovação.

A estratégia de inovação está muito mais ligada à execução prática, ou seja, implementar ideias. No entanto, além de ter boas ideias, deve-se igualmente ter as informações necessárias para embasá-las e as etapas corretas para a perfeita transformação em conhecimento e inovação. Nas seções seguintes serão tratados os fundamentos de Design Thinking (2.1) e Inteligência Estratégica (2.2) aprofundando seus processos, objetivos e suas concepções para relacionar esses conceitos com o gerenciamento estratégico de inovação.

\subsection{DESIGN THINKING}

As empresas sempre utilizaram o design de maneira limitada e como um embelezamento de duas identidades: comunicações ou lançamento de produtos. No entanto ao mesmo passo, buscavam ser inovadoras e inovação conduz à diferenciação. Por mais que não fosse simples de perceber, a diferenciação é alcançada através do design. Pois ele detém habilidades para a identificação de futuros possíveis, para construir pontes com o consumidor e solucionar problemas. Se há a intenção de inovar, há a necessidade de adotar o design (Neumeier, 2010).

O conceito de design não é traduzido apenas pelo que se enxerga ou possa ser manuseado, mas também por sua funcionalidade. Nos últimos anos, muitas empresas começaram a adotar estratégias baseadas em design não somente em seus produtos e serviços, mas no gerenciamento de seus negócios (Terra, 2012).

Ao se pensar no design de forma estratégica, pressupõe-se o uso do Design Thinking - meio de dissociar os conceitos formais, funcionais e estéticos existentes através de um modo de pensar diferente, com a finalidade de delimitar um problema, pensá-lo de modo criativo, gerar soluções, utilizar uma perspectiva multilateral, cocriar, desenvolver novas associações e executar as melhores alternativas (Stickdorn \& Schneider, 2014).

O Design Thinking foi popularizado pela IDEO, empresa de design fundada em 1991 na Califórnia. No entanto, a expressão "Design Thinking" foi utilizada primeiramente por acadêmicos no início da década de 1990 (Pinheiro, 2011). 
De acordo com Martin (2010), o Design Thinking é uma tentativa de traduzir e buscar entender a forma de pensar inovação e métodos inovadores. O conceito sugere que é melhor desenhar futuros alternativos que tenham sentido do que buscar alternativas existentes e torcer para que elas sejam ideais e relevantes para as pessoas.

Nesse contexto, o Design Thinking é definido com o processo que envolve a criação das perguntas corretas para novas soluções e oportunidades dentro do processo de inovação. O foco da abordagem é desenvolver soluções com novas funcionalidades, proporcionar novas experiências, novas formas de enxergar um produto ou serviço no contexto cotidiano e principalmente agregar valor, sendo este o principal objetivo das empresas (Terra, 2012).

O Design Thinking, embora seja uma atividade com foco em criatividade, serve para satisfazer objetivos econômicos tanto quanto criativos. Nesse sentido, trabalha incansavelmente a concepção de oportunidades e hipóteses em seu processo. Elas são resultado das etapas de criação e reciclagem que vão além dos pressupostos do projeto, buscando as melhores soluções e as realmente inovadoras (Ambrose \& Harris, 2011).

Diferentes autores divergem em relação ao número de etapas que compõem a abordagem de Design Thinking (DT). Como afirma Brown e Katz (2010), existem práticas e princípios que levam a um excelente processo de Design Thinking. No entanto, não existe um manual para esse processo, pois as habilidades necessárias são desenvolvidas na prática. Nesse raciocínio, justifica-se a não linearidade das etapas de DT, pois não há uma receita de bolo, mas conceitos correlatos que delimitam os mesmos objetivos no processo.

Dentre as etapas que compõem o Design Thinking, seis são mais recorrentes: etapa do pensamento, pesquisa, ideação, experimentação, desenvolvimento e evolução, descritas no Quadro 1.

\begin{tabular}{|c|c|c|}
\hline Etapa & Descrição & Autores \\
\hline 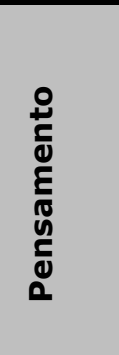 & $\begin{array}{l}\text { Também conhecida como a etapa da descoberta ou imersão, nela se } \\
\text { busca o entendimento sobre o tema ou problema a ser solucionado. Há a } \\
\text { necessidade de um aprofundamento no objetivo e no ponto de partida do } \\
\text { processo. Através das informações do cliente, é possível identificar } \\
\text { restrições mentais que proporcionam um referencial de por onde iniciar o } \\
\text { projeto, além de compreender os objetivos a serem atingidos. Conforme } \\
\text { a evolução do projeto, as restrições do problema por diversas vezes são } \\
\text { desafiadas ou até mesmo mudadas pela equipe ou cliente. É importante } \\
\text { imergir e compreender os limites envolvidos no projeto desde seu início. }\end{array}$ & $\begin{array}{l}\text { Brown e Katz } \\
\text { (2010); } \\
\text { Nitzsche } \\
(2012) .\end{array}$ \\
\hline
\end{tabular}




\begin{tabular}{|c|c|}
\hline $\begin{array}{l}0 \\
\frac{0}{3} \\
\bar{y} \\
y \\
0\end{array}$ & $\begin{array}{l}\text { Na etapa de pesquisa, há a coleta de informações e seu uso para } \\
\text { aprofundamento do tema, por isso ela também pode ser chamada de } \\
\text { etapa de interpretação. Se os consumidores não sabem expressar } \\
\text { diretamente o que gostam ou odeiam, é necessário pesquisar como } \\
\text { vivenciam a experiência da marca, produto ou serviços, para poder } \\
\text { identificar oportunidades implícitas ou disfarçadas. Não é fácil decidir } \\
\text { quais técnicas de pesquisa utilizar, quem observar, quando parar e iniciar } \\
\text { a síntese das informações. Tudo requer prática e o período de observação } \\
\text { pode ser longo, mas, seguindo a premissa de primar pela qualidade e não } \\
\text { pela quantidade, no final serão coletados dados importantes para o } \\
\text { projeto. Assim que os dados são coletados, é necessário analisá-los para } \\
\text { identificar padrões, cujo papel é essencial no processo para a criação de } \\
\text { opções e escolhas pela análise e síntese das informações encontradas. }\end{array}$ \\
\hline 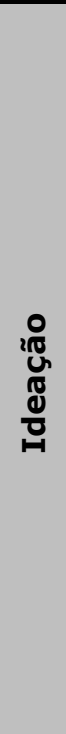 & $\begin{array}{l}\text { E a etapa de criação, em que são geradas as ideias e soluções } \\
\text { relacionadas à questão abordada pelo Design Thinking. Após o } \\
\text { entendimento do tema e a coleta das informações necessárias para } \\
\text { entendê-lo, os designers possuem os insumos para gerar insights e } \\
\text { soluções pertinentes ao problema. Os insights são estímulos ou pequenas } \\
\text { partes de uma informação maior coletada por um indivíduo. Quando há } \\
\text { um conjunto de insights, é possível montar cenários, compreender } \\
\text { relações, hábitos e crenças. Não existe o insight perfeito, mas o que o } \\
\text { torna importante é o que pode ser feito com ele. Esta etapa permite uma } \\
\text { cocriação na busca de novas soluções. Por isso, se faz necessário que ela } \\
\text { seja participativa e que todos os envolvidos tenham conhecimento dos } \\
\text { objetivos do projeto para que sua implementação seja mais assertiva e } \\
\text { possa alcançar os melhores resultados. A criação de ideias no processo } \\
\text { de Design Thinking tem uma transição recorrente entre os estágios de } \\
\text { divergência e convergência. Na fase divergente os designers levantam e } \\
\text { discutem novas opções para o problema e na fase convergente o oposto, } \\
\text { eliminam opções e fazem suas escolhas dentre as ideias sugeridas. Na } \\
\text { revisão desta etapa, é necessário haver um momento de selecionar as } \\
\text { melhores ideias e as mais promissoras para testá-las. }\end{array}$ \\
\hline 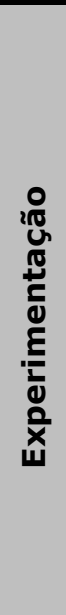 & $\begin{array}{l}\text { Na etapa de experimentação, são feitos os testes, prototipagens das } \\
\text { opções escolhidas. Baseia-se em tirar as ideias do papel para testar se } \\
\text { realmente são boas alternativas. A prototipagem é importante, pois gera } \\
\text { resultado com mais rapidez. Apesar de tomar certo tempo, é a melhor } \\
\text { forma de escolher entre vários direcionamentos possíveis que uma ideia } \\
\text { pode gerar. Quanto antes se tonarem tangíveis as ideias, mais rápido } \\
\text { será possível avaliá-las, aprimorá-las e apontar melhores alternativas. Na } \\
\text { prototipação, procura-se descobrir as ideias que funcionam ou que } \\
\text { podem ser trabalhadas para dar continuidade. Nesta etapa são } \\
\text { eliminados os protótipos de insights que não tenham potenciais. O } \\
\text { desenvolvimento de protótipos deve ser barato e rápido, pois permite a } \\
\text { exploração de ideias paralelas que deverão passar por prototipagem e } \\
\text { necessitam de investimento. A prototipagem resulta no aprendizado do } \\
\text { que se deve ou não fazer, dos melhores meios para chegar ao resultado } \\
\text { almejado e identificar de forma antecipada as barreiras que possam } \\
\text { prejudicar a adoção da nova estratégia escolhida. }\end{array}$ \\
\hline
\end{tabular}

Brown e Katz (2010); Pinheiro (2011) 
Continuação

\begin{tabular}{|c|c|c|}
\hline 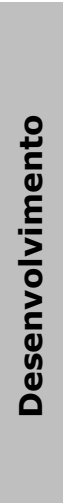 & $\begin{array}{l}\text { Nesta etapa, há a implementação das novas ideias desenvolvidas no } \\
\text { processo de Design Thinking. Após os protótipos serem testados } \\
\text { incansavelmente na etapa de implementação, a equipe concentra-se em } \\
\text { disseminar a ideia de forma clara para ser aceita por toda a empresa, } \\
\text { visando demonstrar e comprovar sua funcionalidade no objetivo } \\
\text { estratégico da organização. O momento de desenvolvimento configura-se } \\
\text { na entrega da solução do projeto de design. A equipe envolvida no } \\
\text { projeto foca a atenção nesta etapa para garantir que os resultados } \\
\text { possam atingir as expectativas de todos os envolvidos. O maior esforço } \\
\text { despendido é para manter o projeto dentro do prazo necessário para que } \\
\text { nenhuma das variáveis sofra algum tipo de alteração que comprometa o } \\
\text { projeto. Esta é a fase mais longa do projeto e também a mais } \\
\text { desafiadora tecnicamente. }\end{array}$ & $\begin{array}{c}\text { Ambrose e } \\
\text { Harris } \\
\text { (2011); } \\
\text { Brown e Katz } \\
\text { (2010); } \\
\text { Nitzsche } \\
\text { (2012) }\end{array}$ \\
\hline 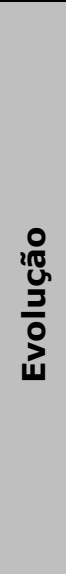 & $\begin{array}{l}\text { A etapa de evolução desenvolve-se pelo feedback da implementação. } \\
\text { Nela as ideias geradas pelo Design Thinking podem evoluir por meio de } \\
\text { mudanças e afinamentos com foco em melhorias e novas alternativas. A } \\
\text { fase de feedback é o momento em que todo o projeto é avaliado com o } \\
\text { objetivo de identificar os aspectos positivos e os que precisam ser } \\
\text { melhorados após o desenvolvimento que a solução implementada foi bem } \\
\text { recebida, quais seus efeitos sobre o público-alvo, como foi a resposta } \\
\text { sobre a solução proposta e qual foi o aprendizado para projetos futuros. } \\
\text { Por mais que pareça ser a última etapa do processo de Design Thinking, } \\
\text { a evolução ocorre ao longo de todo o projeto, pois a cada etapa há a } \\
\text { possibilidade de aprender algo novo que possa abrir novos caminhos e } \\
\text { alternativas para o sucesso do projeto. É importante que em cada etapa } \\
\text { seja observado onde se está, para onde se quer ir, o que está } \\
\text { funcionando bem e o que não está. Mesmo que muita coisa esteja errada, } \\
\text { não se pode parar de evoluir o projeto até que dê certo. }\end{array}$ & $\begin{array}{c}\text { Ambrose e } \\
\text { Harris (2011) }\end{array}$ \\
\hline
\end{tabular}

\section{Quadro 1: Etapas do design thinking}

Fonte: Elaborado pelo autor

Quando se adota o Design Thinking, presume-se a liberdade de imaginar o futuro, criar, propor, inventar e testar mais de uma vez e mais de uma alternativa para o mesmo problema. Isso significa que as empresas devem aprender a interpretar o erro não como uma falha, mas como menos uma opção. O ato de errar é a forma de reduzir as incertezas, é a oportunidade de adquirir novos conhecimentos. As empresas perdem oportunidades por não serem ousadas, por estarem correndo atrás de alternativa mais rápida. 0 Design Thinking busca cocriar a melhor resposta, isso é pensar em design e inovação (Eler, 2011).

Novas ideias possibilitam a inovação por meio do Design Thinking, porém dentro de uma organização essas ideias diferenciadas enfrentam grandes obstáculos. Os principais são sua aceitação e sua divulgação para que todos possam compreendê-la. Com tantas barreiras, as boas ideias acabam por morrer pela burocracia da organização e pelo simples fato de que elas podem abalar as estruturas da empresa, no sentido de questionar o sucesso de estratégias anteriores e transformar os antigos inovadores em atuais conservadores (Brown \& Katz, 2010). 
Miller (2002) destaca que há a necessidade de que os tomadores de decisão e indivíduos do processo tenham as informações necessárias para avaliá-las como possíveis oportunidades. A Inteligência Estratégica é parte importante desse processo, pois, através do monitoramento de seu ambiente pertinente, ela capta sinais e informações que podem fornecer subsídios para os gestores compreenderem a necessidade do Design Thinking ou as soluções geradas por ele.

\subsection{INTELIGÊNCIA ESTRATÉGICA}

Com o desenvolvimento tecnológico e o desenvolvimento da economia global, o ambiente de negócios modifica-se de forma cada vez mais rápida. Isso não é nenhum segredo para os gestores das organizações, que, dessa forma, não podem mais se dar ao luxo de basear suas tomadas de decisão apenas em seu instinto e sua intuição. Com a ferocidade da economia e da concorrência, qualquer decisão deve ser pensada, pois suas consequências influenciam a permanência da empresa no mercado. Dessa forma, pesquisas mostram que a Inteligência Estratégica é importante para o direcionamento do planejamento estratégico das organizações (Passos, 2005).

De acordo com Miller (2002), a inteligência baseia-se na necessidade de que os gestores tenham as informações sobre questões fundamentais do negócio da empresa de forma sistemática e formal. Essas informações, devidamente decupadas e filtradas, tem o objetivo de gerar recomendações para acontecimentos futuros aos tomadores de decisão, proporcionando oportunidades únicas relativas a possíveis decisões que possam fornecer vantagem competitiva.

Para Starec, Gomes e Bezerra (2006), o principal papel da Inteligência Estratégica é dar suporte para a construção e análise dos cenários importantes para a formulação das estratégias corporativas. Essa construção é feita por meio da identificação de sinais que impliquem mudanças no posicionamento competitivo da organização.

Os sinais são identificados através do monitoramento do ambiente pertinente à empresa, o qual visa fornecer informações voltadas ao futuro para que a organização possa estruturar-se de forma precoce contra as ameaças e alavancar as novas oportunidades, ambas ligadas aos atores do ambiente em que está inserida (Lesca \& Janissek-Muniz, 2015). 
Lesca e Janissek-Muniz (2015) ainda ressaltam que o ambiente para o monitoramento é o externo à empresa, o qual é de conhecimento da organização. É necessária a definição de um alvo dentro do ambiente de negócio e que corresponde pelos atores do ambiente, sejam eles diretos ou indiretos, pois suas ações podem gerar grande impacto na empresa.

A representação do ambiente e as informações importantes para a organização objetivam corroborar o processo decisório da empresa e para isso é fundamental a utilização do ciclo de inteligência. Esse ciclo pode ser utilizado para a descoberta das principais questões estratégicas da empresa, que irão delinear os cenários e o monitoramento dos atores em relação às mudanças no ambiente de mercado. Para isso, o ciclo de inteligência deverá ser dinâmico e aplicar um sistema estratégico para geração de alertas antecipados ou radar corporativo (Starec et al., 2006).

Apesar de existirem diversos conceitos de inteligência, percebe-se uma concordância entre diferentes autores sobre a atividade de inteligência no ambiente de negócios. Os principais aspectos de atuação são: ambiente concorrencial (monitoramento dos concorrentes), ambiente externo (monitoramento das mudanças de mercado) e ambiente externo e interno (inclusão das informações internas da organização). Assim, autores compreendem o conceito de inteligência como uma metodologia focada, principalmente, nas informações externas da empresa (Rios \& Janissek-Muniz, 2014).

Para Rios e Janissek-Muniz (2014), a consolidação do método de inteligência tem base em três conceitos: Inteligência Competitiva, por Elisabeth Gomes; Inteligência Estratégica Antecipativa e Coletiva, de Humbert Lesca; Inteligência Competitiva, por Leonard Fuld. Esses três tipos de inteligência configuram a metodologia de inteligência por focarem o ambiente externo a partir do qual se manifestam mudanças importantes com impacto significativo na organização.

Para Gomes (2008), o processo de Inteligência Competitiva apresenta as seguintes fases: identificação de necessidades de inteligência, identificação de necessidades de informação, coleta e armazenamento de informações, análise de informações, disseminação e avaliação dos produtos de inteligência. 
Nas fases de identificação das necessidades de inteligência e necessidade das informações pertinentes, definem-se os objetivos a serem alcançados pela equipe de inteligência. A identificação das necessidades é feita por meio de entrevistas com os indivíduos potenciais usuários dos produtos de inteligência, é por elas que são compreendidos os requisitos de informação e as questões estratégicas e relevantes para a organização (Gomes, 2004). Segundo Gomes (2004), na fase de coleta e armazenamento, são realizadas as atividades de obtenção das informações, classificação das fontes de informação e o tratamento dos dados obtidos ou identificados. Já na análise, transformam-se os dados coletados em uma avaliação completa e confiável para tornar-se um produto de inteligência. Ela é uma síntese das conclusões obtidas sobre o tema que está sendo pesquisado. A disseminação é a fase em que os produtos de inteligência são entregues para os clientes de inteligência. Por fim, a avaliação, que é essencial para o Ciclo de Inteligência, pois a verificação frequente dos produtos de inteligência com os tomadores de decisão possibilita a melhor adequação dos produtos disseminados às reais necessidades da empresa (Gomes, 2004).

Para Fuld (2008), a Inteligência Competitiva é a forma de observar os concorrentes e analisá-los de maneira estratégica a fim de obter vantagem competitiva. Fuld sugere a inteligência competitiva em cinco etapas: planejamento e direção; coleta de informações publicadas; coleta de informações primárias; análise e produção; relatório e informação. Essas etapas formam o Ciclo de Inteligência Competitiva e são importantes de maneira individual, além de apresentar extrema relevância no processo como um todo. As etapas do ciclo são pertinentes para o resultado de inteligência e, caso alguma delas seja eliminada, poderá ocasionar uma análise incompleta ou uma tomada de decisão equivocada.

Lesca e Janissek-Muniz (2015) consideram a Inteligência Estratégica Antecipativa e Coletiva (IEAc) como um processo coletivo e proativo por meio da captação voluntária pelos membros da organização visando coletar informações do ambiente externo, antecipar-se às mudanças que possam surgir e fortalecer a competitividade da organização. $O$ método que operacionaliza a IEAc é o L.E.SCanning, que se divide em nove etapas. O processo inicia-se com a escolha do domínio de aplicação, em que se escolhe qual atividade da empresa terá o reforço da IEAc e, a partir dela, define-se o 
perímetro em que será trabalhado o processo de inteligência. Essa delimitação é chamada de Definição do Alvo da IEAc. Na etapa seguinte, a da coleta de informações, é feita a captação, por meio de uma pesquisa ativa de informações e sinais, de acordo com o alvo definido pela organização. $O$ objetivo é buscar as melhores informações relacionadas aos atores e temas identificados na etapa anterior (Lesca \& Janissek-Muniz, 2015).

Após a coleta, as informações são selecionadas de maneira metódica com base em critérios específicos. Com a seleção das informações capturadas, há necessidade de armazená-las para aproximação e cruzamento dos dados obtidos a fim de que se possam compreender e relacionar os fragmentos de informação (Lesca \& Janissek-Muniz, 2015). Segundo Lesca e Janissek-Muniz (2015), a criação coletiva de sentido é a etapa fundamental no processo de IEAc, pois transforma os sinais fracos e informações coletados no ambiente em potenciais insumos para os tomadores de decisão, com conclusões plausíveis para ações concretas. As etapas finais do processo de IEAc correspondem à etapa de difusão e acesso. A difusão é o repasse das informações, que se caracteriza na transmissão do que foi coletado pelos captadores para os potenciais usuários. Já o acesso é a operação por meio da qual o tomador de decisão pode acessar a informação potencial no momento que lhe for oportuno (Lesca \& Janissek-Muniz, 2015).

Na Figura 1, representa-se o agrupamento das etapas do processo de inteligência por Rios e Janissek-Muniz (2015), com base nos objetivos e nas atividades dos conceitos de inteligência citados anteriormente. 


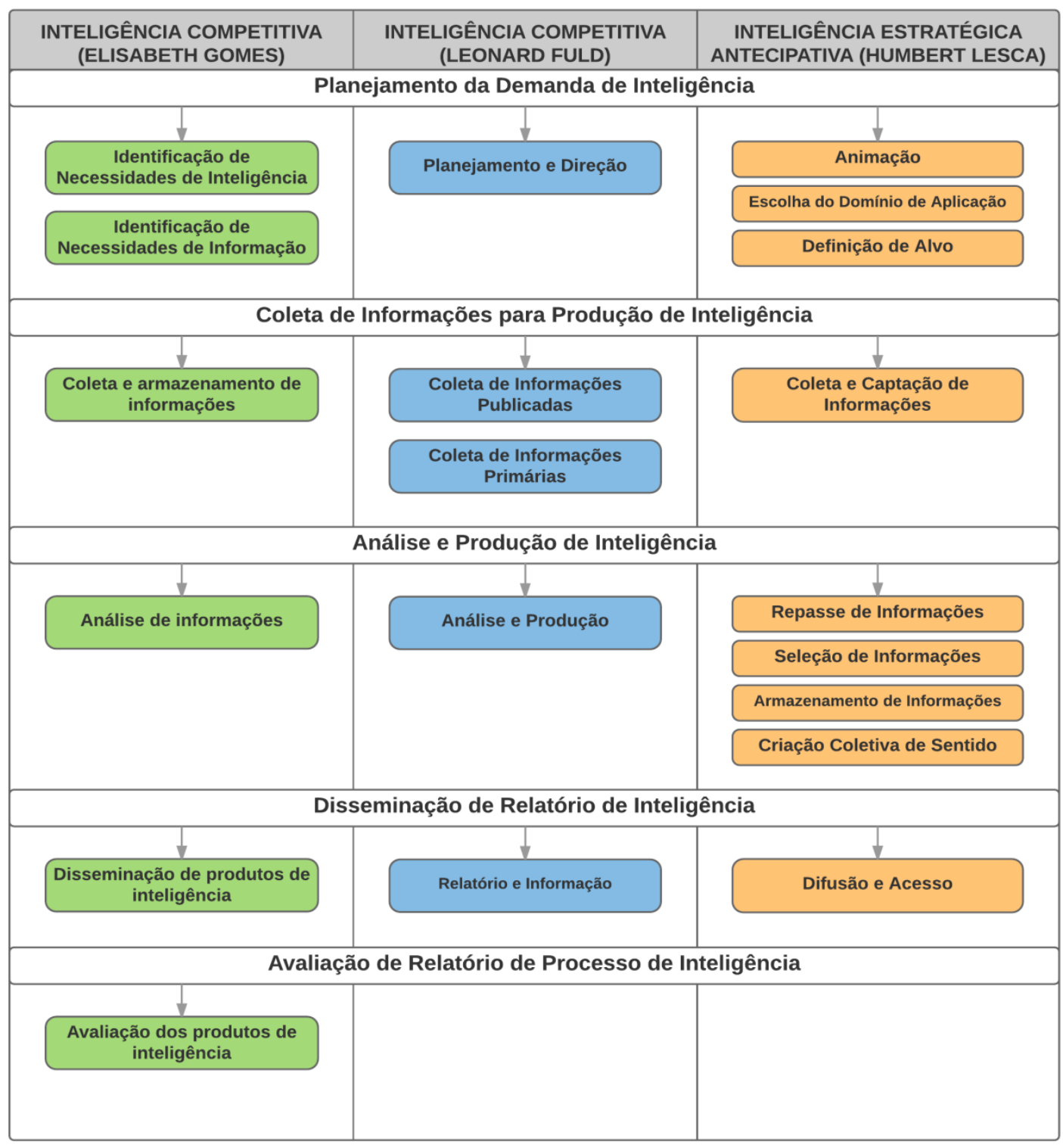

\section{Figura 1: Agrupamento das etapas do processo de inteligência}

Fonte: Adaptada de Rios e Janissek-Muniz (2014)

A finalidade da Inteligência é permitir que a empresa possa agir no momento certo, de forma rápida e eficaz, além de utilizar o mínimo de recursos possíveis. Dessa maneira, ela contribui para o aumento e a sustentação da competitividade da empresa. A Inteligência deve ser percebida como uma ferramenta para a inovação contínua, pois a capacidade de inovar está totalmente relacionada à capacidade de compreender o ambiente externo da organização. Ela é fonte das informações necessárias para escutar o ambiente onde a empresa está inserida, pois é a partir dessas informações que nasce o processo de inovação (Lesca \& Janissek-Muniz, 2015). 


\subsection{ESTRATÉGIA COM FOCO EM INOVAÇÃO}

A maioria das organizações busca ter inovações sem saber exatamente o quer quer encontrar por meio delas. O termo inovação é normalmente associado ao universo das organizações e configura-se como uma revolução na empresa, cheia de mudanças, novos olhares e novas especificações. De certo modo a inovação exerce essa tamanha mudança, mas também é evidente que a inovação em partes pontuais do sistema organizacional pode ser suficiente e rentável para a empresa sem o esforço de uma mudança geral (Terra, 2012).

Terra (2012) ainda afirma que é necessário entender aonde a organização quer chegar antes mesmo de ser inovadora. Para haver uma inovação sistematicamente estabelecida com o planejamento estratégico, é preciso saber onde estão as oportunidades que serão o diferencial no negócio da empresa.

Para Starec (2012), a obtenção de vantagem competitiva está ligada à inovação como parte da cultura organizacional da empresa. Assim, a Inteligência e a Inovação devem caminhar lado a lado no cotidiano da organização. Como exemplo, a Procter \& Gamble (P\&G) é uma das empresas que melhor utiliza o conceito de inovação como estratégia de crescimento. A P\&G implementou uma série de mudanças para tornar-se constantemente inovadora, por conseguinte, materializou um modelo de inovação próprio, que engloba os seguintes aspectos: proposto e valores motivadores, objetivos alargados, estratégias selecionadas, forças nucleares únicas, estruturas possibilitadoras, sistemas consistentes e fidedignos, cultura corajosa e aberta, além de liderança inspiradora.

A Procter \& Gamble é um forte exemplo de estratégia inovativa não só por seus resultados financeiros, mas, por meio do foco em inovação, pelas mudanças nas estratégicas de gestão e na cultura organizacional.

Para adotar uma estratégia com foco em inovação, é necessário reconhecer que as fronteiras de mercado são impostas pelas organizações e não pelo mercado. Dessa forma, o posicionamento da empresa deverá ser na demanda e não na oferta, na criação de valor inovador e não na concorrência. Assim, a organização poderá enxergar além dos limites de competição e, 
utilizando os elementos existentes no mercado, gerar um novo nível de demanda, uma inovação de valor (Kim, 2005).

\section{MÉTODO DE PESQUISA}

A realização de uma pesquisa deve ser sistemática e planejada para assegurar que todos os aspectos do estudo sejam considerados, assim o resultado será consistente com os propósitos e objetivos almejados (Aaaker, 2001). De acordo com Gray (2012), o desenvolvimento de pesquisa é realizado a partir da escolha de um método de coleta de dados, no entanto a definição do método é influenciada pela metodologia de pesquisa escolhida. Já a escolha da metodologia deriva das perspectivas teóricas adotadas pelo pesquisador visando à finalidade da investigação.

Para atingir os objetivos propostos neste estudo, optou-se por uma pesquisa de abordagem qualitativa, exploratória, construtiva e não estruturada. A pesquisa qualitativa é utilizada para saber o que a populaçãoalvo tem em mente. Os dados qualitativos são obtidos para conhecimento de aspectos que não podem ser diretamente medidos ou observados. A abordagem qualitativa com natureza exploratória é usada com o propósito de compreender um problema de maneira geral, considerando suas possíveis variáveis e alternativas. Os métodos não são estruturados, permitindo maior flexibilidade sobre o que será investigado e contribuindo na coleta de diferentes indícios e ideias sobre o mesmo tema (Aaker, 2001).

A fim de obter percepções sobre o contexto do problema, foi realizada a aplicação online de um questionário semiestruturado. Sua elaboração e disseminação foram feitas através do serviço oferecido pelo website Google e pela ferramenta Google Docs. O envio dos questionários foi realizado por email e as mensagens digitais através de link para preenchimento do questionário disponível na web.

Devido ao contexto do estudo basear-se nos conceitos de Design Thinking e Inteligência Estratégica, selecionaram-se, como público-alvo da pesquisa, gestores e profissionais ligados a uma das áreas em questão que tivessem algum conhecimento na área em que não atuam. Os entrevistados foram selecionados por conveniência e abordados principalmente por e-mail, mas também por redes sociais digitais, para participarem da pesquisa. Segundo Aaker (2001), se um pesquisador envia um questionário para uma empresa 
sem destinatário específico, relativiza a amostragem e a identificação dos respondentes. É importante requerer a identificação dos entrevistados e, se possível, ter contato com eles antes de enviar o questionário para ter controle sobre quem verdadeiramente irá respondê-lo.

O questionário foi enviado a profissionais ligados ao Design Thinking (DT) e à Inteligência Estratégica (IE), com cargos variando entre analistas, gestores, designers, professores e diretores, para compreender também a percepção dos tomadores de decisão relacionada ao tema. A amostra da pesquisa foi de 12 respondentes tendo sido enviados aproximadamente 38 questionários. Para a pesquisa, não foram desconsiderados os profissionais com pouco tempo de atuação na área, pois o foco foi na compreensão dos métodos e no potencial de ambos na atual atividade dos entrevistados. Foi delimitada a população que utiliza os processos e a metodologia dos conceitos de DT e IE referenciados neste estudo, além de aplicá-los no contexto mercadológico de estratégia para inovação.

Quanto ao instrumento de coleta, o questionário utilizado foi elaborado com perguntas semiestruturadas, questões abertas, quatro questões objetivas e uma de múltipla escolha, todas relativas à problemática de pesquisa. Ele foi estruturado com base no referencial teórico desenvolvido neste estudo e a partir do detalhamento dos métodos de $D T$ e IE, com o objetivo de auxiliar no comparativo dos dois métodos e na possível relação entre eles como estratégia para o desenvolvimento de inovação.

As perguntas do questionário foram divididas para os dois conceitos dos estudos (DT e IE) de forma que nenhum dos respondentes tivesse dificuldades de responder ou compreender a questão por falta de conhecimento do método. A única questão de múltipla escolha foi utilizada para compreender as etapas do processo envolvendo os conceitos estudados. Nessa questão, foram dispostas, de maneira aleatória, as etapas descritas no referencial, sem menção ao método relacionado. Assim, os respondentes podiam elencar as etapas usadas no dia a dia sem restrição de conceito ou atividade. No Quadro 2, apresenta-se uma síntese dos assuntos abordados no questionário e as fontes que subsidiaram a elaboração das perguntas do instrumento aplicado entre os meses de novembro e dezembro de 2016. 


\begin{tabular}{|c|c|}
\hline Dimensão & Variáveis e Perguntas \\
\hline $\begin{array}{l}\text { Fech } \\
\text { Cor }\end{array}$ & $\begin{array}{l}\text { Resumo dos conceitos de Design Thinking (DT) e Inteligência } \\
\text { Estratégica (IE), contendo quatro perguntas para averiguar como } \\
\text { os profissionais respondentes compreendem cada um dos } \\
\text { métodos, seu uso e objetivo. } \\
\text { 1. Quanto você conhece destes conceitos? } \\
\text { 2. Como você define os conceitos de DT e IE? } \\
\text { 3. O que diferencia DT/ IE de outras metodologias de } \\
\text { inovação? } \\
\text { 4. No caso da utilização do processo de DT e IE em uma } \\
\text { empresa. Como você caracteriza a utilização de cada um } \\
\text { desses métodos? Qual o objetivo deles? }\end{array}$ \\
\hline Público-alvo & $\begin{array}{l}\text { Seleção da amostra conforme público escolhido, com três } \\
\text { perguntas que evidenciam o conhecimento sobre o tema e a } \\
\text { experiência dos entrevistados com ele. } \\
\text { 5. Você trabalha/trabalhou com DT ou IE? Qual dos dois? } \\
\text { 6. Desde quando aplica esse método/processo em seu } \\
\text { trabalho? } \\
\text { 7. Sua função é inteiramente focada em DT ou IE? }\end{array}$ \\
\hline $\begin{array}{l}\text { Etapas do } \\
\text { Processo }\end{array}$ & $\begin{array}{l}\text { Etapas do processo envolvidas nos métodos de DT e IE. Foram } \\
\text { feitas duas perguntas para averiguar quais etapas são utilizadas } \\
\text { pelos profissionais em diferentes objetivos e se utilizam etapas de } \\
\text { ambos os métodos no processo. } \\
\text { 8. Das etapas abaixo, quais são as utilizadas em sua empresa: } \\
\text { ( ) Formação da imagem / problema } \\
\text { ( ) Campo: observação / etnografia } \\
\text { () Identificação das necessidades } \\
\text { () Definição de alvo e domínio } \\
\text { () Apresentação e relatos da experiência de campo } \\
\text { () Animação } \\
\text { () Brainstorming para levantamento de alternativas de solução } \\
\text { () Coleta e armazenamento das informações } \\
\text { () Afunilamento das alternativas } \\
\text { () Análise de informações } \\
\text { () Armazenamento e seleção de informações } \\
\text { () Prototipação } \\
\text { () Criação de sentido } \\
\text { () Aprendizagem e amadurecimento do conceito } \\
\text { () Refinamento do protótipo } \\
\text { () Relatórios e informação final } \\
\text { () Plano de implementação } \\
\text { () Acesso às informações pertinentes } \\
\text { () Disseminação do produto de inteligência } \\
\text { () Comunicação final } \\
\text { () Avaliação } \\
\text { 9. Quais ferramentas são utilizadas nas etapas do processo } \\
\text { (softwares, materiais, entrevistas, desenhos, filmagens)? }\end{array}$ \\
\hline
\end{tabular}

Autor(es)

Brown e Katz (2010); Martin (2010); Miller

(2002); Starec et al. (2006)

Passos (2005); Pinheiro (2011);

Starec et al.

(2006); Terra (2012)
Fuld (2008); Gomes (2004); Lesca e Janissek-Muniz (2015) 
Análise dos métodos. Compreensão de seus objetivos, pontos fracos e principalmente a relação entre eles para obter inovação. O questionário contém cinco perguntas para avaliar se existe relação entre os conceitos de DT e IE e como se manifesta.

10. Quais você diria que são pontos fracos da metodologia e que requerem maior atenção?

11. Quais as recomendações / pontos de controle para conduzir o processo?

12. No seu ponto de vista, existe uma relação entre a aplicação de IE e DT para obter inovação?

Análise do Processo

13. Quais os fatores que determinaram sua resposta na questão anterior?

14. Você acredita que seja possível trabalhar os conceitos DT e IE em conjunto? Explique o motivo.

15. Com foco em inovação, você acredita que as etapas e objetivos do DT e IE sejam sequenciais?

Você acredita que as etapas e objetivos do DT e da IE sejam recorrentes?

Você acredita que as etapas e objetivos do DT e da IE sejam complementares?

Utilização dos conceitos para estratégia de inovação. O questionário contém três perguntas para averiguar a contribuição dos métodos de DT e IE para obtenção de inovação. E, se tendo os mesmos objetivos, possuem alguma relação.

Método 16. Você já conduziu o desenvolvimento de estratégia de

para Inovação inovação aplicando DT ou IE?

17. Como o DT ou IE contribuem para a criação de inovação de valor? Como podem ser mensurados seus resultados?

18. Visando ao mesmo objetivo de inovação, como você define a relação entre DT ou IE?
Continuação

Brown e Katz

(2010); Fuld

(2008); Gomes

(2004); Lesca e Janissek-Muniz

(2015); Miller

(2002); Nitzsche

(2012); Starec

et al. (2006)

\section{Quadro 2: Dimensões e variáveis do instrumento de coleta de dados}

Fonte: Elaborado pelo autor

Os dados obtidos com a aplicação do questionário foram indexados e processados para análise por meio do programa Excel 2010 da Microsoft e pela mesma ferramenta online utilizada para a disseminação da pesquisa, o Google Docs. As questões dissertativas foram analisadas e relacionadas conforme os conceitos abordados na pesquisa teórica. Para a única questão de múltipla escolha da pesquisa, foi realizada análise bivariada e as questões objetivas foram compreendidas e ilustradas por meio de gráficos. 


\section{APRESENTAÇÃO E ANÁLISE dOS RESULTADOS}

Nesta seção, são apresentadas as análises e os resultados precedentes obtidos a partir das informações derivadas da pesquisa e da exploração dos dados obtidos.

A amostra contabilizou 12 entrevistados de acordo com o público-alvo do estudo. Todos os respondentes possuíam conhecimento mínimo dos conceitos de Design Thinking e Inteligência Estratégica e aplicavam pelo menos um dos métodos tema da pesquisa. A amostragem pode ser dividida em três grupos. Dos entrevistados, cinco são profissionais ligados principalmente à Inteligência Estratégica; cinco, ao Design Thinking; e dois utilizam ambos os métodos.

Ao serem questionados sobre o que diferencia Design Thinking e Inteligência Estratégica de outras metodologias de inovação, os entrevistados explicaram que "o maior diferencial está na estruturação da metodologia". Para eles, "DT e IE têm uma visão de negócio, mas também um compromisso com o comportamento das pessoas/etnográfico". Um dos respondentes salientou que "são métodos mais analíticos com foco em análise, resoluções e prevenção de problemas". Outro entrevistado destacou a diferenciação dos conceitos entre si e entre outras metodologias, afirmando que o Design Thinking "possibilita geração de ideias em volume com grande nível de aprofundamento" e a Inteligência Estratégica "a capacidade de identificar oportunidades criando cenários".

Conforme Stickdorn e Schneider (2014), o Design Thinking tem como a finalidade delimitar um problema, pensá-lo de modo criativo e gerar soluções. Para Starec et al. (2006), o principal papel da Inteligência Estratégica é dar suporte para construção e análise dos cenários importantes para formulação das estratégias corporativas. Quando perguntado sobre o objetivo desses conceitos e como caracteriza sua utilização, um dos entrevistados apontou:

O Design Thinking é uma forma estruturada de gerar ideias e solucionar problemas com um olhar de análise e síntese, gerando conexões e ideação rápida. A Inteligência Estratégica foca no uso do pensamento estratégico para tomada de decisão através da busca de informações (imersão) e da criação de sentido e significado estratégico a partir das informações coletadas.

Para outro entrevistado a percepção é de que:

A Inteligência Estratégica reúne informações sobre concorrentes, mercado, consumidores e cenário econômico para municiar tomadas de decisões e lançamento de produtos e serviços. Com base nessas informações, entra o Design Thinking, que é pensar na usabilidade do que a empresa oferece dada essa análise prévia. 
Em relação à Inteligência Estratégica, Gomes (2004), Fuld (2008) e Lesca e Janissek-Muniz (2015) definem, conforme a Figura 1 deste estudo, as etapas que compõem o processo de IE. Para Brown e Katz (2010) e Nitzsche (2012), as etapas que compõem o processo de Design Thinking estão especificadas no Quadro 1 do estudo. A partir dessas informações, os profissionais de DT e IE foram questionados sobre quais etapas do processo são utilizadas em suas organizações e as mais presentes nas respostas dos entrevistados foram identificação das necessidades, brainstorming para levantamento de alternativas de solução, coleta/armazenamento das informações e análise de informações, conforme Gráfico 1.

No Gráfico 1, por meio da quantidade de etapas indicadas pelos respondentes, é possível verificar uma mescla entre as etapas dos conceitos de Design Thinking e Inteligência Estratégica sendo utilizada nas empresas dos profissionais entrevistados.

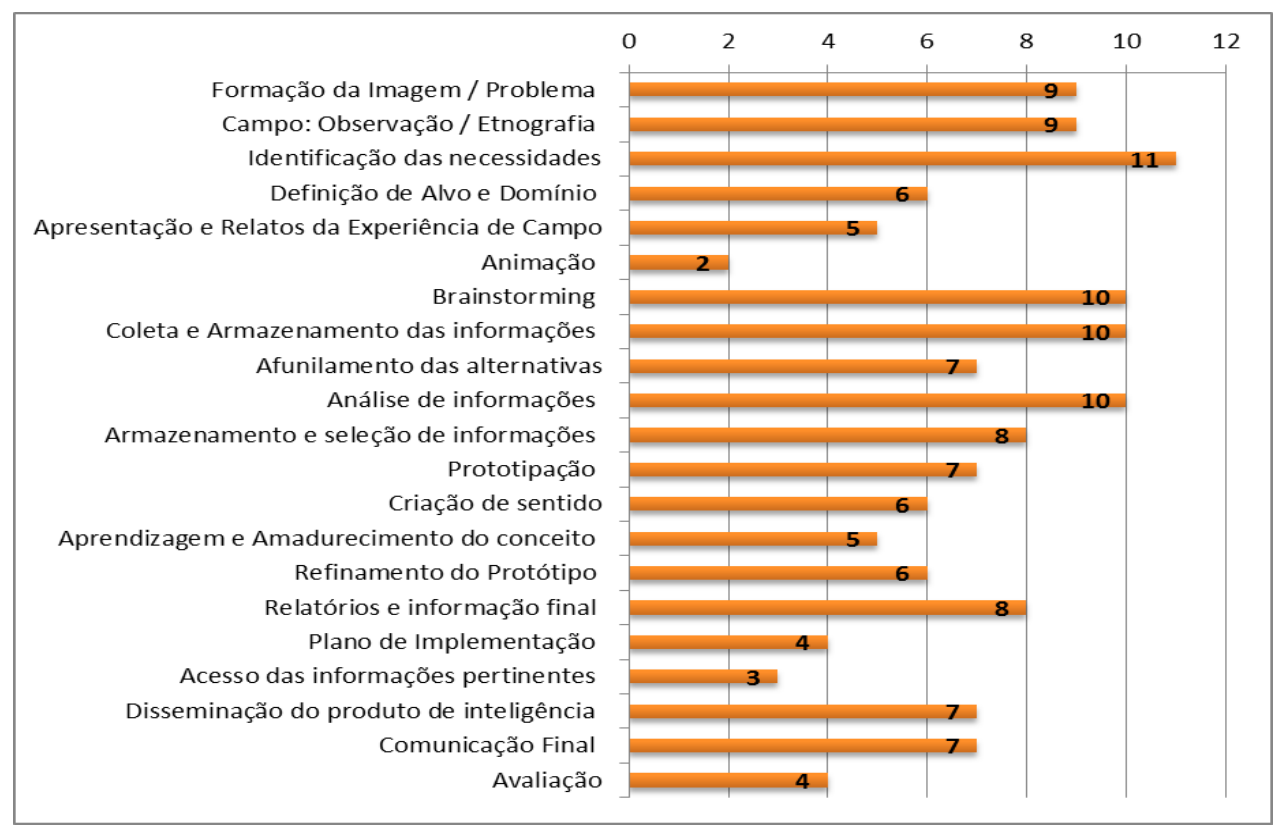

\section{Gráfico 1: Etapas do processo nas organizações}

Fonte: dados da pesquisa (2016)

Das ferramentas utilizadas nas etapas do processo desenvolvido pelos entrevistados, as mais citados foram Canvas, Analytics, entrevistas (em profundidade e em grupo), QlikView, Nielsen, post-its e observação participante.

As ferramentas acima elencadas, contudo, não são vistas como as principais para a aplicação de Design Thinking ou Inteligência Estratégica, mas são as 
mais recorrentes no que se refere às principais atividades citadas no referencial teórico e que se aplicam ao mercado.

Sobre o questionamento de quais os pontos fracos do método e que requerem maior atenção, os respondentes afirmaram que, não importando ser Design Thinking ou Inteligência Estratégica, o que deve ter atenção são as pessoas, aquelas envolvidas no processo e que são necessárias para o resultado final. Além do envolvimento completo, um dos entrevistados salientou que é necessário "acreditar no que foi construído para a tomada de decisão". Outro, por sua vez, destacou:

Como todo trabalho em grupo, é importante que todos estejam em sintonia e com vontade de solucionar os problemas e seguir o plano do grupo, sem cortes ou censura, com cabeça aberta, e também que tenham bagagens diversas para tornar a discussão mais dinâmica e produtiva.

O que requer maior atenção é a condução do processo, o comprometimento de todos, o cuidado na interpretação das informações obtidas e a valorização das etapas, como afirmou um dos entrevistados:

Acredito que no Design Thinking é a condução do processo. Por ser multidisciplinar, precisa ter pessoas envolvidas e comprometidas com a condução. Na inteligência, acredito que o maior cuidado deve ser na interpretação dos dados, que, se enviesados, comprometem o processo de tomada de decisão.

Especificamente para o conceito de Design Thinking, um dos pontos de atenção e como ponto fraco é a etapa de prototipagem. Os respondentes destacaram que o apoio na prototipagem é essencial para o projeto e a qualidade na execução desta etapa.

Pinheiro (2011) afirma que a prototipagem resulta no aprendizado do que se deve ou não fazer, dos melhores meios para chegar ao resultado almejado e identificar de forma antecipada as barreiras que possam prejudicar a adoção da nova estratégia escolhida.

Como recomendações e pontos de controle do processo, os entrevistados mencionaram principalmente o apoio dos tomadores de decisão, coordenação ativa, animação constante, problema claro, sistematização, descentralização, envolvimento de todas as áreas e prática constante do método.

Ao serem questionados sobre a relação entre Inteligência Estratégica e Design Thinking para obter inovação, 92\% entrevistados afirmaram existir uma relação entre os dois conceitos. Apenas um dos entrevistados se absteve da resposta (Gráfico 2).

Os respondentes indicaram a existência de relação entre a prática dos dois conceitos como "resultado de experiências profissionais". Além de que "ambos podem gerar conhecimentos cruciais para a empresa, gerando inovação, que podem até determinar a sustentabilidade da empresa".

De acordo com um dos entrevistados, os conceitos são convergentes para obter inovação: "A lógica do Design Thinking pode ser inserida dentro 
da Inteligência Estratégica: definição do problema, imersão, abrir/fechar, ideação, prototipagem, geração de soluções rápidas a partir de um processo multidisciplinar".

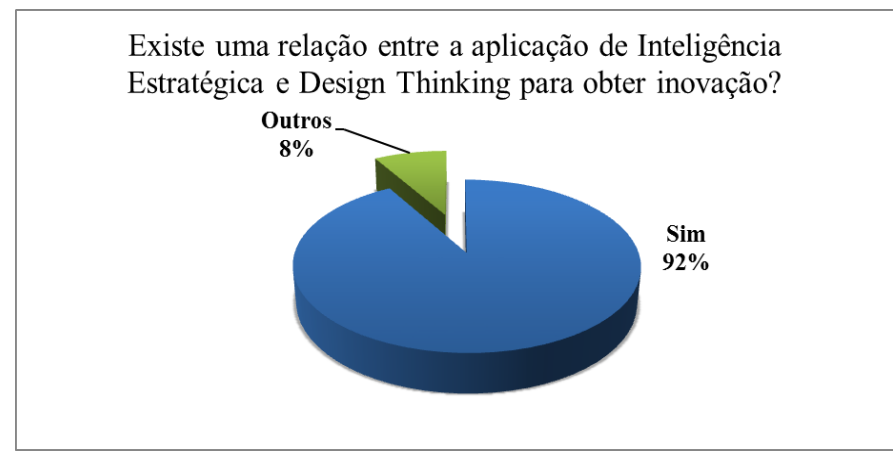

\section{Gráfico 2: Relação entre Inteligência Estratégica e Design Thinking para obter inovação}

Fonte: dados da pesquisa (2016)

A partir do questionamento sobre a relação entre os conceitos de Design Thinking e Inteligência Estratégica, os entrevistados responderam sobre a possibilidade de trabalhar os dois conceitos em conjunto. A consolidação das respostas mostrou ser possível, pois, como salienta um dos respondentes, "é possível fazer o Design Thinking e gerar produtos de Inteligência com base nos resultados. Pode-se, através dos resultados de Inteligência, fazer uma imersão utilizando Design Thinking".

Para subsidiar a afirmativa de existir a possibilidade de trabalhar os conceitos Inteligência Estratégica e Design Thinking, em diferentes respostas foi utilizado o termo "complemento" pela similaridade entre os processos e seus objetivos.

Os pesquisados responderam a três questões objetivas sobre a associação entre os conceitos de DT e IE. Eles foram questionados se os conceitos tema do estudo eram sequenciais, recorrentes ou complementares tendo o foco em inovação. Houve $83 \%$ de afirmação positiva entre os entrevistados que declararam que os conceitos podem ser sequenciais e complementares. Também $75 \%$ confirmaram a possibilidade de serem utilizados de maneira recorrente, como ilustrado nos Gráficos 3, 4 e 5.

Para um dos entrevistados, a associação entre os conceitos existe, pois "são feitos em ciclos, processos podem ser revisados continuamente. Mas devem ser respeitadas as etapas do Design Thinking e da Inteligência". Outros afirmaram que "ambas podem andar juntas" e que

Elas têm uma estrutura, uma teoria que define um ciclo, mas que dão liberdade para serem retomadas e refeitas a qualquer momento. Podendo ser sequenciais, mas não necessariamente. O ideal é que o processo de Design Thinking seja o recheio de um sanduíche entre dois processos de Inteligência Estratégica.

Dessa forma, as principais relações entre Design Thinking e Inteligência Estratégica são de sequencialidade e complementariedade. 
Com foco em inovação você acredita que as etapas e

objetivos do Design Thinking e Inteligência Estratégica são sequenciais?

m $\operatorname{Sim}=$ Não

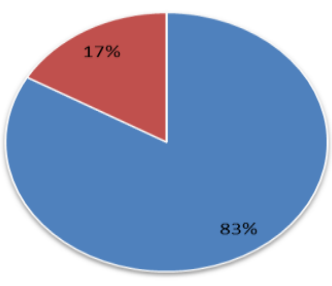

Gráfico 3: Inteligência Estratégica e Design Thinking são sequenciais?

Fonte: dados da pesquisa (2016)

Você acredita que as etapas e objetivos do Design Thinking e da Inteligência Estratégica são recorrentes?

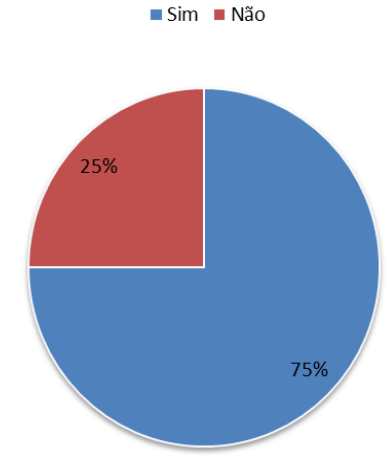

\section{Gráfico 4: Inteligência Estratégica e Design Thinking são recorrentes?}

Fonte: dados da pesquisa (2016)

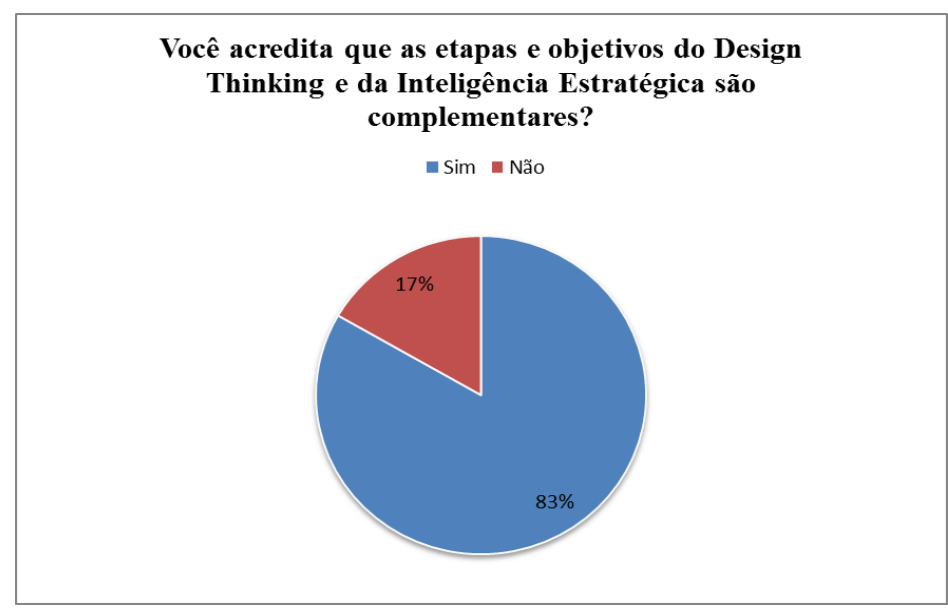

\section{Gráfico 5: Inteligência Estratégica e Design Thinking são complementares?}

Fonte: dados da pesquisa (2016) 
Para Starec (2012), a obtenção de vantagem competitiva está ligada à inovação como parte da cultura organizacional da empresa. Assim, a Inteligência e a Inovação devem caminhar lado a lado no cotidiano da organização.

Na criação de inovação de valor, os métodos de DT e IE contribuem gerando informações valiosas que através do coletivo podem auxiliar em seu desenvolvimento. Para os entrevistados, elas "contribuem como ferramentas", também "sustentam a base estratégica, além da aprendizagem gerada e o envolvimento das pessoas".

Para os respondentes, o resultado de uma estratégia inovativa com base nos dois conceitos é difícil de ser mensurado devido a sua subjetividade, pois "a mensuração está mais ligada ao tipo de problema e solução aplicada". Reconhecem ainda que "a mensuração dos resultados só pode se dar na prática. A prototipagem dá alguma segurança, mas não o suficiente para saber se aquela ideia terá sucesso ou não, pois entram aí outros fatores externos".

A última questão abordada no questionário foi a de como os pesquisados definiam a relação entre Inteligência Estratégica e Design Thinking visando ao mesmo objetivo de inovação. Para os respondentes, "são métodos excelentes que se completam, geram conhecimentos necessários para a tomada de decisão". Em outras palavras, possuem uma relação de proximidade e complementariedade.

Um dos respondentes afirmou: "Eu definiria a relação entre ambos os conceitos como uma complementaridade estratégica com foco na inovação" e também que são "dois processos que podem ser desenvolvidos em conjunto".

Em relação à utilização de ambos de maneira sequencial, "o Design Thinking auxilia a IE na busca do novo e que pode ser o diferencial para a empresa". Por fim atestaram que entre Design Thinking e Inteligência Estratégica a "relação é simbiótica e complementar dentro de um objetivo de inovação", pois o "Design thinking é mais pragmático e objetivo e deve ser antecedido por um trabalho de inteligência estratégica para que se chegue à melhor pergunta/problema a ser solucionada".

\section{CONCLUSÕES}

O objetivo deste estudo foi compreender a existência de uma possível correlação entre os conceitos de Design Thinking e Inteligência Estratégica para o desenvolvimento de inovação. Com base nas informações consolidadas no referencial teórico, foi possível ter maior entendimento sobre os conceitos de Inteligência Estratégica e Design Thinking, além de suas 
utilidades em estratégia inovativa. O estudo possibilitou uma síntese das etapas que compõem os dois métodos e, por meio da pesquisa, um comparativo entre ambos em relação a suas aplicações no mercado.

De acordo com a análise realizada, foi possível compreender que Design Thinking e Inteligência Estratégica possuem diferenças em relação ao método, envolvimento e etapas. No entanto dispõem de características similares como conceito analítico, foco em resolução e prevenção de problemas.

Ao analisar a pesquisa, foi observado que os dois conceitos dependem essencialmente de material humano. As pessoas envolvidas no processo precisam de uma boa condução e animação para o envolvimento total nas etapas e a concretização dos objetivos almejados.

Na identificação da possível relação entre o Design Thinking e a Inteligência Estratégica, pode-se perceber a existência de uma associação entre os dois conceitos para obtenção de inovação.

Os participantes da pesquisa definiram a ligação dos métodos de DT e IE como "complementos". Reforçando a possibilidade de utilização como complementaridade conforme a necessidade da organização e o foco estratégico. Além de complementares, os conceitos de Inteligência Estratégica e Design Thinking podem ser sequenciais, como observado na pesquisa, pois podem "andar juntos" e, já que seus métodos se definem e ciclos, nem sempre estruturados, dão liberdade para serem retomados ou alterados conforme a necessidade estratégica. Dessa maneira, proporcionam uma sequencialidade entre as etapas e os conceitos.

É importante salientar que o Design Thinking e a Inteligência Estratégica são conceitos independentes já aplicados no mercado com objetivos totalmente distintos. Neste estudo, o objetivo foi compreender melhor as similares e correlação entre os métodos com o propósito de considerar o emprego dos dois conceitos em conjunto para aplicação de estratégia inovativa.

Desse modo, conclui-se que existe uma relação de proximidade e complementariedade entre o Design Thinking e a Inteligência Estratégica quando aplicados dentro de um mesmo objetivo. Nesse cenário, ambos se tornam necessários para o planejamento estratégico da organização.

Esta pesquisa limitou-se a uma pesquisa bibliográfica sobre os conceitos tema do estudo e à aplicação de um questionário com profissionais de Design Thinking e de Inteligência, conhecedores dos conceitos ou atuantes no mercado. Sendo o tema ainda pouco explorado, a análise aqui lançada pode servir de inspiração para aprofundamentos relacionados ao assunto, futuras pesquisas sobre a correlação entre os conceitos, além de novas pesquisas para aumentar a bibliografia disponível. 


\section{REFERÊNCIAS}

Aaker, D. A. (2001). Pesquisa de marketing. São Paulo: Atlas.

Ambrose, G., \& Harris, P. (2011). Design thinking (M. Belloli Trad.). Porto Alegre: Bookman.

Ben-Israel, R. (2012). O futuro da inovação. PUCRS Informação, 33(160), 24.

Brown, T., \& Katz, B. (2010). Design thinking: uma metodologia poderosa para decretar o fim das velhas ideias (C. Yamagami Trad.). Rio de Janeiro: Elsevier.

Collet, L. (2012). Mensuração das inovações: construção de um índice de ciência, tecnologia e inovação (ICT\&I) para os estados brasileiros.

Dissertação de Mestrado, Faculdade de Administração, Contabilidade e Economia da Pontifícia Universidade Católica do Rio Grande do Sul, Porto Alegre, RS, Brasil..

Eler, D. (2011, junho-julho). Design thinking para gestores. T\&D: Inteligência Corporativa, 169, 32-39.

Fuld, L. M. (2008). Intelligence software report. Massachusetts: Fuld Company.

Gomes, E. (2004). Inteligência competitiva: como transformar informação em um negócio lucrativo. Rio de Janeiro: Campus.

Gomes, E. (2008). Apostila da disciplina de inteligência competitiva do curso MBA em gestão de negócios e inteligência competitiva. Rio de Janeiro: Senac.

Gray, D. E. (2012). Pesquisa no mundo real (2a ed.). Porto Alegre: Penso.

Janissek-Muniz, R., Lesca, H., \& Freitas, H. (2011, abril/junho). Inteligência estratégica antecipativa e coletiva para tomada de decisão. Revista Inteligência. Competitiva, 1(1), 102-127. Recuperado em 3 de setembro, 2016, de

http://www.inteligenciacompetitivarev.com.br/ojs/index.php/rev/article/vi ew/6/15

Júlio, C. A. (2005). A arte da estratégia: pense grande, comece pequeno e cresça rápido. Rio de Janeiro: Elsevier.

Kim, W. C. (2005). A estratégia do oceano azul: como criar novos mercados e tornar a concorrência irrelevante. Rio de Janeiro: Elsevier.

Lesca, H., \& Janissek-Muniz, R. (2015). Inteligência estratégica antecipativa e coletiva: o método L.E.SCAnning $®$. Porto Alegre: Pallotti. 
Martin, Roger L. (2010). Design de negócios: por que o design thinking se tornará a próxima vantagem competitiva dos negócios e como se beneficiar disso. Rio de Janeiro: Elsevier.

Miller, J. P. (2002). O milênio da inteligência competitiva (R. Rubenich Trad.). Porto Alegre: Bookman.

Neumeier, M. (2010). A empresa orientada pelo design (F. José Nonenmacher Trad.). Porto Alegre: Bookman.

Nitzche, R. (2012). Afinal, o que é design thinking? São Paulo: Rosari.

Oliveira, D. de P. R. de. (2001). Planejamento estratégico: conceitos, metodologia e práticas (16a ed.). São Paulo: Atlas.

Passos, A. (2005). Inteligência competitiva: como fazer IC acontecer na sua empresa. São Paulo: LCTE.

Pinheiro, T. (2011). Design thinking Brasil: empatia, colaboração e experimentação para pessoas, negócios e sociedade. Rio de Janeiro: Elsevier.

Rios, F. L. C, \& Janissek-Muniz, R. (2014). Uma proposta de relação de requisitos funcionais para um software de apoio ao processo de inteligência. Revista Eletrônica de Administração - REAd, 20(2), 425-460.

Santos, M. J. (2014). Orientação ao consumidor e performance financeira: uma análise do papel da capacidade de inovação de produto. Tese de Doutorado, Faculdade de Administração, Contabilidade e Economia da Pontifícia Universidade Católica do Rio Grande do Sul, Porto Alegre, RS, Brasil.

Starec, C., Gomes, E., \& Bezerra, J. (Orgs). (2006). Gestão estratégica da informação e inteligência competitiva. São Paulo: Saraiva.

Starec, C. (2012). Gestão da informação, inovação e inteligência competitiva: como transformar a informação em vantagem competitiva nas organizações. São Paulo: Saraiva.

Stickdorn,, M., \& Schneider, J. (2014). Isto é design thinking de serviços: Fundamentos, ferramentas, casos. Porto Alegre: Bookman.

Terra, J. C. C. (2012). 10 dimensões da gestão da inovação: uma abordagem para a transformação organizacional. Rio de Janeiro: Elsevier. 